\title{
A prospective study of insulin resistance among infertile women with polycystic ovarian syndrome
}

\author{
M. Smitha, S. Jyothi*, Anand Acharya
}

Department of Obstetrics and Gynecology, Konaseema Institute of Medical Science Amalapuram, Andra Pradesh, India

Received: 12 July 2018

Accepted: 06 August 2018

*Correspondence:

Dr. S. Jyothi,

E-mail:jyothi.s@gmail.com

Copyright: (c) the author(s), publisher and licensee Medip Academy. This is an open-access article distributed under the terms of the Creative Commons Attribution Non-Commercial License, which permits unrestricted non-commercial use, distribution, and reproduction in any medium, provided the original work is properly cited.

\begin{abstract}
Background: Insulin plays a key role in producing hyperandronism and suppression of insulin secretion in women with PCOS is associated with decreased cytochrome P450c17 . cytochrome P450c17 $\alpha$ is a bifunctional enzyme present in ovary is a key enzyme for androgen synthesis. Various studies have been conducted regarding association of insulin resistance with PCOS in infertile patients but there is no study is available about this in our area. So we have designed this study to evaluate insulin resistance in infertile patients with PCOS in rural Andhra Pradesh.

Methods: The study population include 180 untreated patients who attended the infertility clinic in outpatient department of obstetrics with infertility due to different cause that include polycystic ovarian disorder also. They have been selected for this study randomly based on inclusion and exclusion criteria.

Results: The mean value of glucose insulin ratio was 5.146+2.611 in group A and $8.62+5.55$ in group B the P value was 0.004909 . The mean of LH/FSH ratio was $1.78+0.423$ in group A and $1.02+0.042$ in group B. The P value was $<0.00001$. The mean of HOMA IR was $8.375+2.68$ in group A and $3.03+1.09$ in group $\mathrm{B}$, with $\mathrm{P}$ value $<0.00001$. The mean value of QUICKI was $0.2815+0.0002875$ in group A and $0.347+0.10$ in group B with $\mathrm{P}$ value $<0.00001$. Mean serum DHEAS level was $275.59+53.48$ in infertile patient with PCOS and $208.48+36.11$ in infertile patients without PCOS. The p value was 0.00012 .

Conclusions: Based on present study we would like to conclude that the body mass index was high among infertile women with PCOS and a greater number of women presented with acanthosis. There was decrease insulin sensitivity and increase insulin resistance among infertile women with poly cystic ovarian disease, in rural area of Andhra Pradesh and that is not different from the study of other part of world.
\end{abstract}

Keywords: Insulin resistance, Infertility, Polycystic ovarian disease

\section{INTRODUCTION}

In year 1935 stein and eventual first described reproductive disorder characterised as a syndrome of oligo- menorrhea, infertility, infertility, obesity and polycystic ovaries poly cystic ovarian syndrome is one of the most common multifactorial endocrinal disorder effecting 5 to $15 \%$ of the women in the general population as per Rotterdam criteria in 1980 George A Burgan et al in there study on polycystic ovarian disease concluded that there was a striking positive correlation between hyperandrogenism and hyperinsulinism in PCOD with relatively wild glucose tolerance, which is not due to simple obesity. ${ }^{1-4}$ Since last three to four decades various studies have established that PCOS (polycystic ovarian syndrome) is associated with insulin resistance, decreased insulin sensitivity, metabolic abnormalities and infertility. Obesity plays an additive synergistic effect on PCOS. ${ }^{5,6}$ Insuline plays a key role in producing hyperandronism and suppression of insulin secretion in women with PCOS is associated with decreased cytochrome P450c17 $\alpha$. cytochrome P450c17 $\alpha$ 
is a bifunctional enzyme present in ovary is a key enzyme for androgen synthesis. ${ }^{5-7}$ Various studies have been conducted regarding association of insulin resistance with PCOS in infertile patients but there is no study is available about this in our area. So, we have designed this study to evaluate insulin resistance in infertile patients with PCOS in rural Andhra Pradesh.

\section{METHODS}

Present study is a prospective randomized observational cross-sectional study conducted in the department of obstetrics and Gynaecology Konaseema institute of medical science Amalapuram from July 2015 to May 2018 .

\section{Study population}

The study population include 180 untreated patients who attended the infertility clinic in outpatient department of obstetrics with infertility due to different cause that include polycystic ovarian disorder also. They have been selected for this study randomly based on inclusion and exclusion criteria.

\section{Inclusion criteria}

- $\quad$ Age range from 20 to 40 years.

- Not treated for infertility before.

\section{Exclusion criteria}

- History of diabetes and hepatic disorder.

- OC pills taken with lost three months.

- Thyroid disorder

\section{Ethics}

This study is approved by institutional ethics committee. A written informed consent was taken from women before enrolment into this study

\section{Method}

A standard predesigned form was used to take the medical history of all the patients for uniformity. Proper menstrual history, regularity, presence of Hirsutism, acanthosis nigricans, was noted. The cause of infertility was established by laboratory investigation, hysterosalpingography, laparoscopy and hysteroscopy in addition to proper clinical evaluation. For the diagnosis of PCOS Rotterdam's criteria was used. Women diagnosed with infertility were randomly selected for this study and divided into two groups. ${ }^{8}$

Group A = infertility due to PCOS

Group B = infertility without PCOS due to another cause.

Parameters like Age, BMI (body mass index), fasting plasma glucose, overnight fasting plasma insulin, Dehydroepiandrosterne sulphate, (mcg/dl) (DHEAS), LH, FSH, LH/FSH ratio, HOMA IR (homeostasis model assessment of insulin resistance) and quantitative insulin sensitivity check index (QUICKI) and fasting serum plasma glucose to insulin ratio was measured in both group of patients. HOMA IR was calculated by formula fasting insulin (mIU/ml x fasting glucose $(\mathrm{mg} / \mathrm{dl}) / 405 .{ }^{9}$ insulin sensitivity QUICKI was calculated by formulae $(1 / \log$ insulin $+1 / \log$ glucose $) .{ }^{10}$ For estimation of other parameters COBASE 411 immuno -chemistry analyser was used. Blood sample were collected during the follicular phase between the second and the fourth day of menstrual cycle for LH and FSH.

\section{Statistical analysis}

Data obtained was entered into spss 16.0 software and data was analysed by unpaired T-test $\mathrm{P}$ value less than 0.05 was considered statistically significant.

\section{RESULTS}

During the study period one hundred eighty patients with infertility were enrolled for this study, and divided into two groups, having 90 patients in each group. As per table 1 regarding demography of the patients in both groups, in group A mean age of the patient was $28.22+6.440$ years and in group B mean age was $34.775+5.897$ years, with $P$ value 0.341019 . The mean body mass index (BMI) was $25.33+2.4649 \mathrm{~kg} / \mathrm{m}^{2}$ in group $\mathrm{A}$ and $21.94 \mathrm{~kg} / \mathrm{m}^{2}$ in group $\mathrm{B}$, the $\mathrm{P}$ value was $<0.00001$. The duration of infertility in group $\mathrm{A}$ was $2.3625+1.225$ years and in group B it was $2.3825+1.0425$ with $\mathrm{P}$ value $<0.1469$.

Table 1: Demography of the patients.

\begin{tabular}{|c|c|c|c|c|}
\hline Variables & & Group A $(\mathrm{n}=90)($ Mean \pm SD $)$ & Group B $(\mathrm{n}=90)($ Mean \pm SD $)$ & P value \\
\hline Age & & $28.225 \pm 6.440$ & $34.775 \pm 5.8792$ & 0.341019 \\
\hline BMI & & $25.33 \pm 2.4649$ & $21.94 \pm 1.65$ & $<0.00001$ \\
\hline Duration of & ty (in year) & $2.3625 \pm 1.225$ & $2.3825 \pm 1.0425$ & $<0.4691$ \\
\hline \multirow[b]{2}{*}{ Acanthosis } & Present & 64 & 14 & \multirow{2}{*}{$\begin{array}{l}\text { Chi square } \\
\text { statistic }=56.5611 \\
P \text { value }<0.0001\end{array}$} \\
\hline & Absent & 26 & 76 & \\
\hline
\end{tabular}


Out of 90 patients in group acanthosis was present in 64 patients and absent in 26 patients but in group B it was present in 14 patients and absent in 76 patients with $\mathrm{P}$ value $<0.00001$. As per Table 2 regarding comparison of hormonal profile and insulin sensitivity /resistance between two group, the fasting plasma glucose mean value in group B was $118.75+16.62 \mathrm{mg} / \mathrm{dl}$ but in group B it was $99.65+8.993 \mathrm{mg} / \mathrm{dl}$ with $\mathrm{P}$ value $<0.00001$.

Table 2 comparison of hormonal profile and insulin sensitivity/resistance between two groups.

\begin{tabular}{|llll|}
\hline Variables & Group A $(\mathrm{n}=90)($ Mean + SD $)$ & Group B $(n=90)($ Mean + SD $)$ & P value \\
\hline FPG $(\mathrm{mg} / \mathrm{dl})$ & $118.75 \pm 16.62$ & $99.65 \pm 8.993$ & $<0.00001$ \\
\hline FPI & $26.678 \pm 9.382$ & $12.88 \pm 5.35$ & $<0.0001$ \\
\hline LH MIU/ml & $10.46 \pm 2.38$ & $5.48 \pm 1.462$ & $<0.0001$ \\
\hline FSH MIU/ml & $6.59 \pm 1.26$ & $6.28 \pm 2.20$ & 0.226 \\
\hline Glucose/insulin ratio & $5.146 \pm 2.611$ & $8.62 \pm 5.55$ & 0.004909 \\
\hline LH/FSH & $1.78 \pm 0.423$ & $1.02 \pm 0.0482$ & $<0.0001$ \\
\hline HOMA IR & $8.375 \pm 2.68$ & $3.03 \pm 1.09$ & $<0.0001$ \\
\hline QUICKI & $0.2815 \pm 0.0002875$ & $0.347 \pm 0.100$ & $<0.0001$ \\
\hline DHEAS $(\mathrm{mcg} / \mathrm{dl})$ & $275.79 \pm 53.48$ & $208.48 \pm 36.11$ & 0.00012 \\
\hline
\end{tabular}

The fasting plasma insulin was $26.678+9.382 \mathrm{mIU} / \mathrm{L}$ in group and $12.88+5.35 \mathrm{mIU} / \mathrm{L}$ in group $\mathrm{B}$. The $\mathrm{P}$ value was $<0.0001$. The serum LH mean value in group A was $10.46+2.38 \mathrm{mIU} / \mathrm{ml}$ and $5.48+1.462 \mathrm{mIU} / \mathrm{ml}$ in group B with $\mathrm{P}$ value $<0.00001$. Mean FSH level was $6.59+1.26$ $\mathrm{MIU} / \mathrm{ml}$ in group $\mathrm{B}$, with $\mathrm{P}$ value 0.226 . The mean value of glucose insulin ratio was $5.146+2.611$ in group A and $8.62+5.55$ in group $\mathrm{B}$ the $\mathrm{P}$ value was 0.004909 . The mean of $\mathrm{LH} / \mathrm{FSH}$ ratio was $1.78+0.423$ in group $\mathrm{A}$ and $1.02+0.042$ in group B. The $\mathrm{P}$ value was $<0.00001$. The mean of HOMA IR was $8.375+2.68$ in group A and $3.03+1.09$ in group $\mathrm{B}$, with $\mathrm{P}$ value $<0.00001$. The mean value of QUICKI was $0.2815+0.0002875$ in group A and $0.347+0.10$ in group $\mathrm{B}$ with $\mathrm{P}$ value $<0.00001$. Mean serum DHEAS level was $275.59+53.48$ in infertile patient with PCOS and $208.48+36.11$ in infertile patients without PCOS. The p value was 0.00012 .

\section{DISCUSSION}

During two and half year of study period one hundred eighty infertile women with or without PCOS were included in this study having rural background. In present study we have evaluated insulin resistance among infertile women with PCOS in comparison with infertile women without PCOS. In present study we have found that statically the mean ages of both group of patients are same, there is no significant difference between two $(\mathrm{P}$ value $=0.341019$ ). This finding corroborates with the work of Moamor et al, but Madani $\mathrm{T}$ et al has found significant difference in the age of two group and was higher in patient with PCOS patient which does not support the finding in our patients. ${ }^{2,5} \mathrm{We}$ have found that there is highly significant statistical difference between two groups with regard to BMI (body mass index) BMI was higher in PCOS patient. This finding is supported by the work of Abdelazim IA et al. ${ }^{6}$ This finding also corroborates with the finding of Haq $\mathrm{F}$ et al. ${ }^{11}$ The duration of infertility was not different statistically in both group $(\mathrm{P}=0.4091)$. This finding is supported by the work of Jefout MA et al. ${ }^{5}$ There is statistically significant difference between presence of acanthosis in both group $(\mathrm{P}<0.00001)$. This finding is in agreement with the finding of Mandrelle $\mathrm{K}$ et al, but this finding is not supported by the observation of Jefout MA et al.,12 Fasting plasma glucose was significantly higher in PCOS patients with infertility in comparison with control, which is supported by the work of Chitme HR et al and Svendsen et al. ${ }^{13,14}$ Fasting plasma insulin was also significantly higher in group A then group B (P $<0.00001)$, this finding corroborates with the finding of Chitme HR et al and Jefout MA et al. 5,13

Glucose to insulin ratio was significantly lower in PCOS patients then the control $(\mathrm{P}=0.004909)$. this finding is supported by the study of Stovall DW et al, but the study of Chitme HR et al the mean of glucose to insulin ratio was higher in cases then control but it was not significant statistically. ${ }^{14,15}$ Homa IR was significantly higher in patients with PCOS then control $(\mathrm{P}<0.00001)$, which is supported by the work of Waker K et al, Stovall et al and Chitme HR et al. ${ }^{13,15,16}$ QUICKI value was also significantly lower in our patients with PCOS in comparison to control; this finding is supported by the work of Delphine Wilma SC et al, Chitme HR et al. And Abdelazim IA et al., ${ }^{6,13}$ These results in present study indicate a well-established state of insulin resistance among our patients with PCOS. In present study we have found that serum LH level was significantly higher in PCOS patient then control but there in not significant difference in FSH level between two groups but the ratio of LH and FSH was significantly higher in group A, this is supported partially by the work of Moamar et al but supported by the work of Banaszecska B et al and Khanamk et al. ${ }^{5,18,19}$ There is significant difference in mean DHEAS concentration in both group with $\mathrm{P}$ value 
0.00012.Mean DHEAS concentration was higher in PCOS group. Kathleen Brennan et al found that DHEAS is negatively correlated to insulin resistance in PCOS but the mechanism by which DHEAS affects insulin resistance in PCOS is unknown. ${ }^{20}$

\section{CONCLUSION}

Based on present study we would like to conclude that the body mass index was high among infertile women with PCOS and a greater number of women presented with acanthosis. There was decrease insulin sensitivity and increase insulin resistance among infertile women with poly cystic ovarian disease, in rural area of Andhra Pradesh and that is not different from the study of other part of world. LH level was high and DHEAS level was also high in our patients. So, for the treatment of PCOS insulin resistance must be considered and should be correlated with decrease in insulin and DHEAS concentration.

\section{Funding: No funding sources}

Conflict of interest: None declared

Ethical approval: The study was approved by the Institutional Ethics Committee

\section{REFERENCES}

1. Stein IF, Leventhal ML. Amenorrhea associated with bilateral polycystic ovaries. Am J Obstet Gynecol. 1935;29:181-91.

2. Madani T, Hosseini R, Ramezanali F, Khalili G, Jahangiri N, Ahmadi J, et al. Metabolic syndrome in infertile women with polycystic ovarian syndrome. Arch Endocrinol Metabol. 2016;60(3):199-204.

3. Fauser BC, Tarlatzis BC, Rebar RW, Legro RS, Balen $\mathrm{AH}$, Lobo R, et al. Consensus on womens health aspects of polycystic ovary syndrome (PCOS). Human Reprod. 2012;27(1):14-24.

4. Burghen GA, Givens JR, Kitabchi AE. Correlation of hyperandrogenism with hyperinsulinism in polycystic ovarian disease. J Clinical Endocrinol Metabol. 1980;50(1):113-6.

5. Al-Jefout M, Alnawaiseh N, Al-Qtaitat A. Insulin resistance and obesity among infertile women with different polycystic ovary syndrome phenotypes. Scientific Rep. 2017;7(1):5339.

6. Ibrahim A, Abdelazima W, Farok E., Metabolic syndrome among infertile women with polycystic ovary syndrome Asian Pacific J Reprod. 2015;4(1):44-8.

7. Nestler JE, Jakubowicz DJ. Decreases in ovarian cytochrome P450c17 alpha activity and serum free testosterone after reduction of insulin secretion in polycystic ovary syndrome. N Engl J Med. 1996;335(9):617-23.

8. Rotterdam ESHRE/ASRM-Sponsored PCOS Consensus Workshop Group 2004 Revised 2003 consensus on diagnostic criteria and long-term health risks related to polycystic ovary syndrome. Fertil Steril. 2004;81(1):19-25.

9. Matthews DR, Hosker JP, Rudenski AS, Naylor BA, Treacher DF, Turner RC. Homeostasis model assessment: insulin resistance and beta-cell function from fasting plasma glucose and insulin concentrations in man. Diabetologia. 1985;28(7):412-9.

10. Katz A, Nambi SS, Mather K, Baron AD, Follmann DA, Sullivan G, Quon MJ. Quantitative insulin sensitivity check index: a simple, accurate method for assessing insulin sensitivity in humans. J Clinical Endocrinol Metabol. 2000;85(7):2402-10.

11. Haq F, Aftab O, Rizvi J, Clinical, biochemical and ultrasonographic features of infertile women with polycystic ovarian syndrome. JCPSP. 2007;17(2):7680.

12. Mandrelle K, Kamath MS, Bondu DJ, Chandy A, Aleyamma TK, George K. Prevalence of metabolic syndrome in women with polycystic ovary syndrome attending an infertility clinic in a tertiary care hospital in south India. J Human Reprod Sci. 2012;5(1):26.

13. Havagiray RC, Eman AA, Anfal MA, Buthina MAB, Zamzam KA, Maisa MAT, et al Insulin Sensitivity and Resistance in Infertile Women with Polycystic Ovary Syndrome. J Gynecol Women's Health. 2017;6(5):555700.

14. Svendsen PF, Nilas L, Nørgaard K, Jensen JE, Madsbad S. Obesity, body composition and metabolic disturbances in polycystic ovary syndrome. Hum Reprod. 2008;3(9):2113-21.

15. Stovall DW, Bailey AP, Pastore LM. Assessment of Insulin Resistance and Impaired Glucose Tolerance in Lean Women with Polycystic Ovary Syndrome. J Womens Health (Larchmt). 2011;20(1):37-43.

16. Kauffman RP, Baker VM, DiMarino P, Gimpel T, Castracane VD. Polycystic ovarian syndrome and insulin resistance in white and Mexican American women: a comparison of two distinct populations. American J Obstetrics Gynecol. 2002;187(5):1362-9.

17. Wilma DS, Kavya N, Kulkarni S. Evaluation of insulin sensitivity status in polycystic ovarian syndrome. Asian Pacific J Trop Dis. 2011;1(1):67-70.

18. Banaszewska B, Spaczynski RZ, Pelesz M, Pawelczyk L. Incidence of elevated $\mathrm{LH} / \mathrm{FSH}$ ratio in polycystic ovary syndrome women with normo-and hyperinsulinemia. Rocz Akad Med Bialymst. 2003;48(1):131-4.

19. Khanam K, Parvin M. An Observational Study on 100 Patients with Polycystic Ovarian Syndrome (PCOS). J Enam Med College. 2014 Jan 1;4(3):156-60.

20. Brennan K, Huang A, Azziz R. Dehydroepiandrosterone sulfate and insulin resistance in patients with polycystic ovary syndrome. Fertil Steril. 2009;91(5):1848-52.

Cite this article as: Smitha M, Jyothi S, Acharya A. A prospective study of insulin resistance among infertile women with polycystic ovarian syndrome. Int J Reprod Contracept Obstet Gynecol 2018;7:3786-9. 